\title{
Memory Consolidation for the Discrimination of Frequency-Modulated Tones in Mongolian Gerbils Is Sensitive to Protein-Synthesis Inhibitors Applied to the Auditory Cortex
}

\author{
Michaela Kraus, ${ }^{1}$ Horst Schicknick,${ }^{2}$ Wolfram Wetzel, ${ }^{1}$ Frank Ohl, ${ }^{1}$ Sabine Staak, ${ }^{1}$ and \\ Wolfgang Tischmeyer ${ }^{1,3}$ \\ ${ }^{1}$ Leibniz Institute for Neurobiology, D-39008 Magdeburg, Germany; ${ }^{2}$ FAN GmbH, Magdeburg, Germany
}

\begin{abstract}
Differential conditioning of Mongolian gerbils to linearly frequency-modulated tones (FM) has recently received experimental attention. In the study of the role of cerebral protein synthesis for FM discrimination memory, gerbils received post-training bilateral injections of anisomycin into the auditory cortex under light halothane anesthesia. Compared with saline-treated controls, anisomycin-treated gerbils showed a discrimination decrement during the subsequent three days of training. They markedly improved their performance within training sessions, but started each session at low levels. When repeatedly trained gerbils received post-session injections of anisomycin, discrimination performance during subsequent sessions was similar to the pre-injection performance, indicating that retention, retrieval, reconsolidation, and expression of the established reaction were not affected. However, the improvement of a partially established discrimination reaction was impaired after this treatment. Intracortical injections of emetine confirmed this finding. Neither drug affected FM discrimination learning when given several days before the initial training. Our results suggest that protein-synthesis inhibitors applied to the auditory cortex of gerbils during the post-acquisition phase interfered with learning and memory-related aspects of FM processing. The resulting deficit was evident for a number of post-injection training days. This effect was probably due to impaired consolidation, i.e., processes required for long-term stabilization or retrieval of the memory trace while leaving short-term memory intact.
\end{abstract}

Long-term plastic changes in the brain, including those supporting memory formation, are assumed to depend on permanent functional alterations in neural cells that require reprogramming of gene expression (Goelet et al. 1986; Alkon et al. 1991; Armstrong and Montminy 1993; Weiler et al. 1995; Dudai 1996; Alkon 1998). Experimental evidence derived from a variety of species and learning paradigms is indicative for consolidation processes that are relevant for stabilization and/or retrieval of long-term memory (McGaugh 2000). These processes are sensitive to disruption by interfering events and agents, such as electroconvulsive shock, inhibition of protein synthesis, or brain injury. Inhibition of cerebral protein synthesis at the level of transcription or translation was shown to disrupt processes supporting long-term memory formation in animals including insects (e.g., DeZazzo and Tully 1995; Menzel 2001), mollusks (e.g., O'Leary et al. 1995; Bailey et al. 1996; Carew 1996; Ramirez et al. 1998; Casadio et al. 1999), birds (e.g., Ng et al. 1991; Ribeiro and Mello 2000; Rose 2000), and rodents

${ }^{3}$ Corresponding author.

E-MAIL tischmeyer@ifn-magdeburg.de; FAX 49-391-6263229.

Article and publication are at http://www.learnmem.org/cgi/doi/ $10.1101 / \mathrm{lm} .47502$ (e.g., Matthies 1989; Rosenblum et al. 1993; Lamprecht and Dudai 1996; Quevedo et al. 1999; Schafe et al. 2001). Longterm memory formation consists of multiple phases. Characteristically, the formation of long-term memory is sensitive to protein-synthesis inhibitors applied within narrow time windows around or after acquisition. (For review, see Davis and Squire 1984; Stork and Welzl 1999; Izquierdo and McGaugh 2000.) However, some findings have suggested that the same manipulations that cause memory loss after initial learning may also lead to loss of that memory after its reactivation or retrieval. (For review, see Sara 2000.) Thus, a recent study implies that inhibition of protein synthesis can interfere with reactivated as well as new memories (Nader et al. 2000). It has been suggested that, when retrieved, memories may reenter a labile state and require reconsolidation processes in order to be maintained.

The auditory cortex of mammals is believed to be the substrate for particular aspects of auditory stimulus processing, mediating certain forms of auditory performance as well as playing a role in auditory learning (e.g., Weinberger and Diamond 1987; Aitkin 1990; Bakin and Weinberger 1990; Scheich 1991; Recanzone et al. 1993; Weinberger 1995; Ehret 1997; Scheich et al. 1997; Weinberger 1998;

LEARNING \& MEMORY 9:293-303 @ 2002 by Cold Spring Harbor Laboratory Press ISSN1072-0502/02 \$5.00

$$
\begin{array}{lllllllllllllll}
\text { L } & E & A & R & N & I & N & G & \mathcal{Q} & M & E & M & O & R & Y
\end{array}
$$


Edeline 1999; Ohl et al. 2001). Previous studies on the Mongolian gerbil (Meriones unguiculatus) have revealed physiological correlates of learning-related changes in the auditory cortex of this small desert rodent. Thus learning-induced alterations of neuronal activity patterns have been demonstrated through the use of metabolic labeling techniques (Scheich et al. 1993b; Scheich and Zuschratter 1995; Scheich et al. 1997). Moreover, single- and multi-unit electrophysiology revealed that the receptive fields of single units in the gerbil auditory cortex show learning-induced plasticity (Ohl and Scheich 1996; Ohl and Scheich 1997). Lesion studies have suggested that the gerbil auditory cortex plays a critical role in discriminating the directions of modulation of linearly frequency-modulated tones (FM) (Ohl et al. 1999). The lesion effects on FM discrimination were compatible with both the hypothesis of a purely sensory deficit in FM processing and the hypothesis of an involvement of the auditory cortex in mechanisms of learning and memory.

The following experiments were performed to define the role of cerebral protein synthesis in differential conditioning of gerbils to FM. Our findings suggest that posttraining bilateral injections of the protein-synthesis inhibitors anisomycin (ANI) or emetine (EME) into the auditory cortex impair processes required for formation and/or retrieval of long-term, but not short-term, memory of the FM discrimination reaction.

\section{RESULTS}

Gerbils were trained daily to discriminate between rising and falling tones. Learning behavior and performance were studied in a GO/NO-GO task aiming at avoidance of a mild foot shock by crossing the hurdle in a two-way shuttle box. The discrimination performance was quantified by the measure $D$, i.e., the difference between the relative frequencies of hurdle crossings in response to the reinforced and unreinforced stimuli. Protein-synthesis inhibitors were bilaterally applied to the auditory cortex, and the effect of treatment in relation to control-injected animals was tested in subsequent training sessions performed every $24 \mathrm{~h}$. Three sets of experiments were performed. In the initial experiment, gerbils received injections of ANI after completion of the first training session. In a second set of experiments, gerbils were repeatedly trained to attain either a fully or a partially established discrimination reaction before post-session injections of ANI or EME were performed. In a third set of experiments, drugs were administered several days before the initial training.

Three gerbils were used to validate our procedure of positioning the injection tracks using the 2-deoxyglucose autoradiography. Brains of injected animals were horizontally cut $(40 \mu \mathrm{m})$ and the sections were exposed to autoradiographic analysis as detailed elsewhere (Ohl et al. 1999). Each injection yielded an injection track visible in the hori- zontal sections. Metric analysis confirmed the proper placement of the injection sites in the primary (AI), anterior (AAF), and posterior (DP/VP) fields of the auditory cortex (see Scheich et al. 1993a; Budinger et al. 2000a). A representative case is shown in Figure 1.

\section{Effects of ANI Injected After Initial Training}

In an examination of the sensitivity of a newly acquired FM discrimination reaction to protein-synthesis inhibitors, gerbils received injections of saline or of a $113 \mathrm{mM}$ solution of ANI into the auditory cortex twice: immediately and $2 \mathrm{~h}$ after completion of the initial training session. The effect of treatment was tested in subsequent training sessions performed on three consecutive days. Figure $2 \mathrm{~A}$ compares the discrimination rates $D$ of ANI-treated gerbils with those of the control-injected animals. An analysis of variance (ANOVA) over sessions across treatment groups revealed significant main effects of treatment $\left(F_{(1,19)}=5.81 ; P\right.$ $<0.05)$ and session $\left(F_{(3,57)}=8.51 ; P<0.001\right)$ and no significant treatment $x$ session interaction $\left(F_{(3,57)}=1.49\right)$. The significant effect of session in conjunction with the lack of a significant treatment $\mathrm{x}$ session interaction implies that both treatment groups were able to improve their discrimination rates over sessions. The significant effect of treatment indicates a decrement in the discrimination performance of gerbils that received injections of $113 \mathrm{mM}$ ANI when compared with saline-treated gerbils.

To further analyze the performance decrement monitored after injections of $113 \mathrm{mM}$ ANI, the discrimination rates $D$ were calculated for the initial 24 trials (referred to as block A) and the remaining 36 (referred to as block B) of each training session. ANOVA over the post-injection training sessions across treatment groups and blocks revealed a significant main effect of treatment $\left(F_{(1,19)}=11.36 ; P\right.$ $<0.005)$ but not of block $\left(F_{(1,19)}=2.64\right)$. The treatment $\mathrm{x}$ block interaction reached nearly the level of statistical significance $\left(F_{(1,19)}=4.00 ; P=0.055\right)$. These findings indicate again a significant difference between the discrimination rates of ANI-treated gerbils and controls, whereas the discrimination rates monitored in blocks $\mathrm{A}$ and $\mathrm{B}$ did not significantly differ from each other. The finding that the interaction between treatment and block nearly reached the level of statistical significance might point to an uneven expression of the effect of treatment in blocks A and B. Indeed, this is reflected in the patterns of performance shown in Figure 2B. ANI-treated gerbils markedly improved their discrimination scores within the post-injection training sessions, but showed low levels of performance in block A, or at the beginning, of each of the sessions. Saline-treated controls did not show this type of behavior. Planned comparisons revealed significant differences between treatment groups in block A of sessions $3\left(t_{(19)}=2.34, P<0.05\right)$ and $4\left(t_{(19)}=2.22, P<0.05\right)$ but not in block $\mathrm{B}$ of sessions 3 $\left(t_{(19)}=0.27, P>0.7\right)$ and $4\left(t_{(19)}=1.11, P>0.2\right)$.

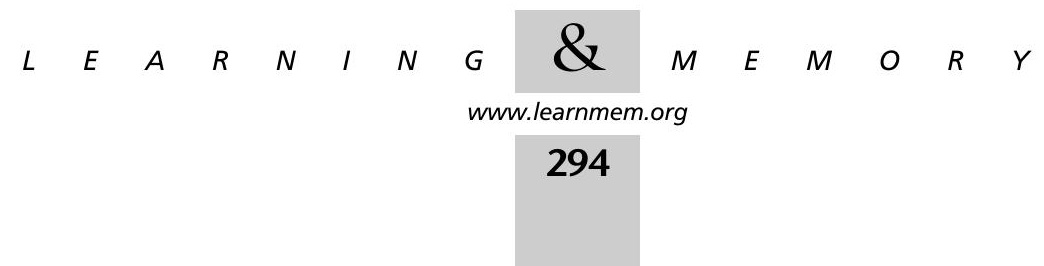




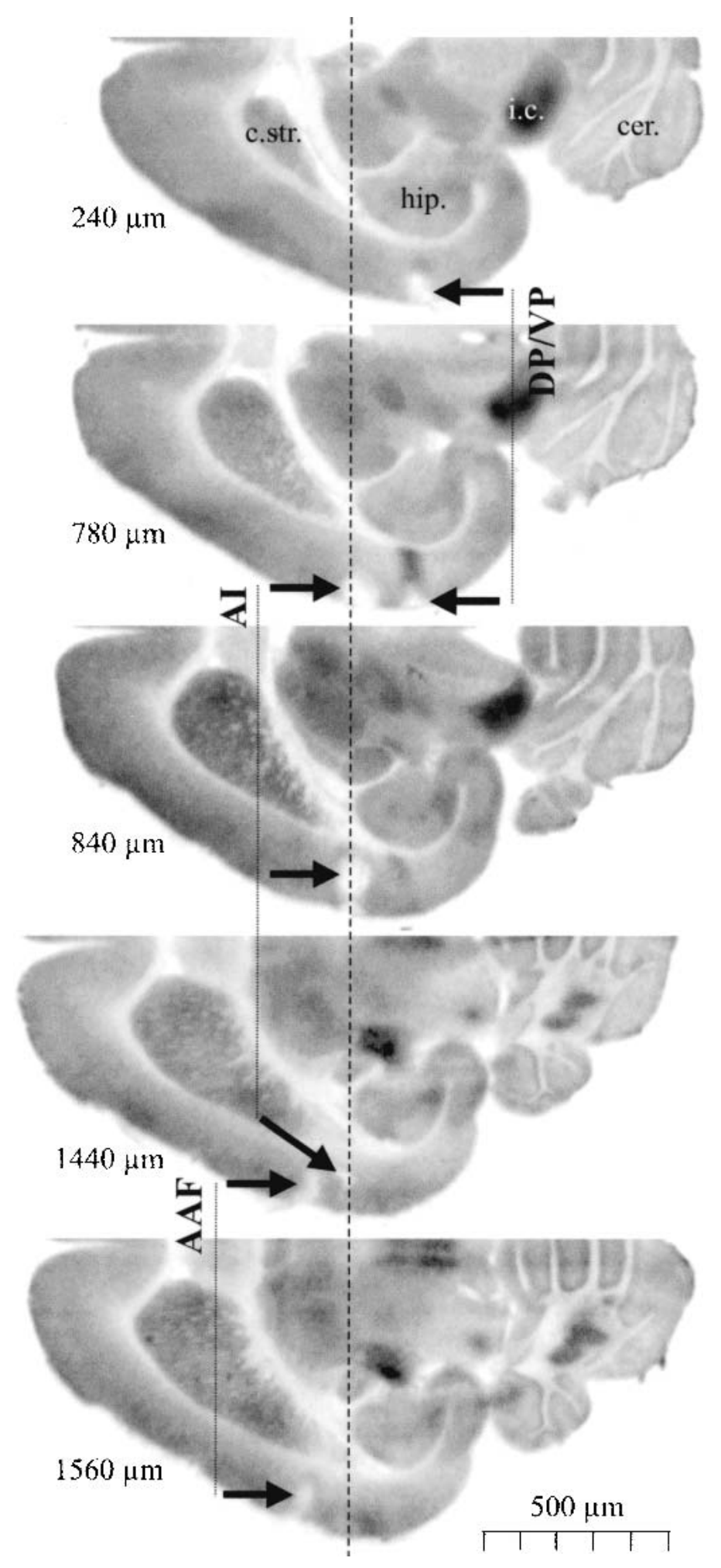

Figure 1 Localization of injection sites using 2-deoxyglucose autoradiography in a representative case. Five autoradiographs of horizontal sections through the left brain hemisphere of a gerbil having received $1 \mu$ injections into the auditory cortical primary (AI), anterior (AAF), and posterior (DP/VP) fields are shown. For each section its dorsoventral position is indicated as referenced to the dorsal tip of the corpus striatum (cf. Scheich et al. 1993a). The injection tracks for each of the auditory cortical fields are marked by arrows connected with solid lines. The dashed line marks the rostrocaudal position of the anterior tip of the hippocampus along which sections were aligned and which provides a suitable anatomical landmark for referencing the position of the individual cortical fields (Scheich et al. 1993a; Budinger et al. 2000a) and the corresponding injection tracks. Other abbreviations: c.str. corpus striatum; cer. cerebellum; i.c. colliculus inferior; hip. hippocampus.

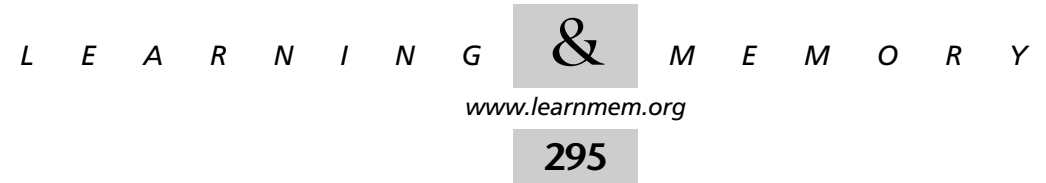



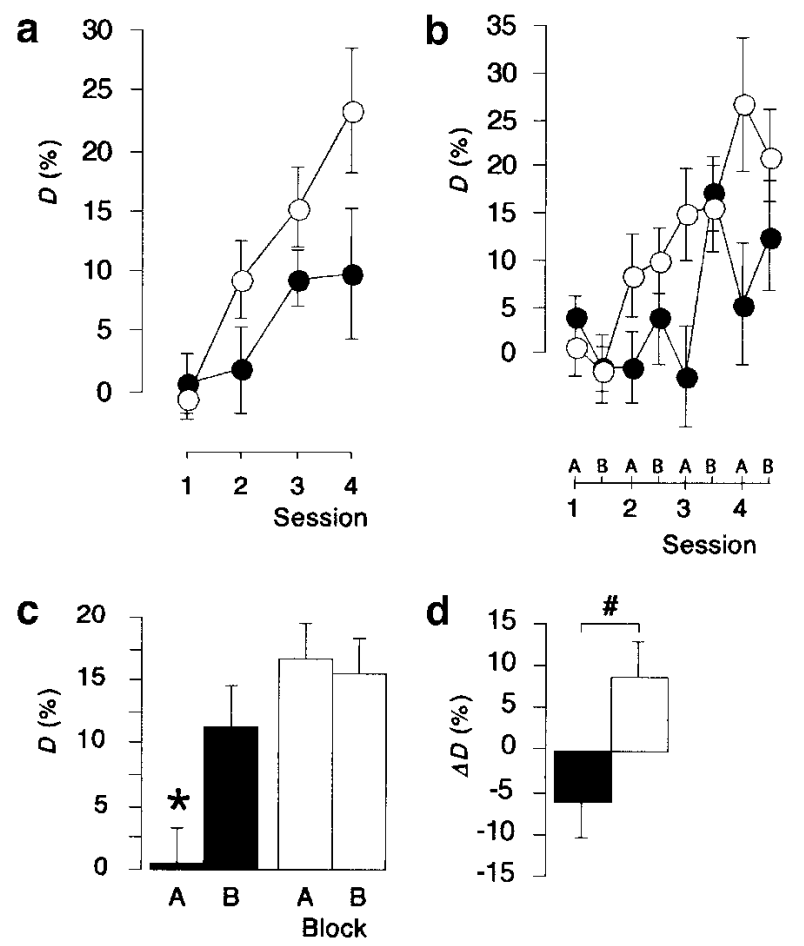

Figure 2 Post-training injections of protein-synthesis inhibitor anisomycin ( $\mathrm{ANI}$ ) impaired frequency-modulated tone (FM) discrimination learning. Gerbils were trained on the FM discrimination task every $24 \mathrm{~h}$. Saline (open symbols, $n=10$ ) or $113 \mathrm{mM}$ ANI (filled symbols, $n=11$ ) were bilaterally injected twice, i.e., immediately after and $2 \mathrm{~h}$ after completion of the first training session. The discrimination rates $D$ estimated (a) across all four training sessions or (b) across the initial 24 (block A) and final 36 (block B) trials of all four training sessions are shown. (c) Discrimination rates $D$ estimated across blocks $A$ and $B$ are expressed as averages of sessions 2 to $4\left[{ }^{*}\right)$ significantly different from the values in block $B$ of ANI-treated gerbils and in blocks $A$ and $B$ of saline-treated contols (t-test)]. $(d)$ The inter-session differences $\Delta D$, i.e., the differences between $D$ recorded in block $A$ of a given session and in block $B$ of the preceding session, are expressed as averages of all three inter-session intervals [(\#) significant difference between treatment groups $(t$-test)]. All data points represent group means \pm S.E.M.

The same pattern of results is reflected in Figures 2C and $2 \mathrm{D}$. Figure $2 \mathrm{C}$ shows the discrimination rates averaged over the post-injection training sessions. The mean discrimination rate of ANI-treated gerbils monitored in block A was significantly lower than those monitored in block B of the same group $\left(t_{(10)}=2.60, P<0.05\right)$ and in blocks $\mathrm{A}\left(t_{(19)}\right.$ $=4.03, P<0.001)$ and $\mathrm{B}\left(t_{(19)}=3.67, P<0.002\right)$ of controls. In contrast, the mean discrimination rate of ANItreated gerbils monitored in block B did not significantly differ from those monitored in blocks A $\left(t_{(19)}=1.23, P\right.$ $>0.2)$ and $\mathrm{B}\left(t_{(19)}=0.96, P>0.3\right)$ of controls. Moreover, the mean discrimination rate of controls monitored in block A did not significantly differ from the level in block B of the same group $\left(t_{(19)}=0.26, P=0.8\right)$. This latter finding suggests that, in contrast to the ANI-treated group, the major increase in the discrimination performance of controls oc- curred between block $\mathrm{B}$ of a given session and block $\mathrm{A}$ of the following session, rather than within the training sessions. Indeed, the mean inter-session differences shown in Figure 2D differed significantly between groups $\left(t_{(19)}=2.50, P<0.025\right)$. They exhibited positive values for controls but negative values for ANI-treated gerbils, indicating that, on average, the discrimination rates of controls increased whereas those of ANI-treated gerbils decreased between the final part of a given session and the initial part of the following one.

To look for side effects of ANI on mechanisms that may interfere with the learning performance, general parameters (such as footshock intensities and avoidance times, i.e., the times required to enter the goal compartment in response to the $\mathrm{CS}+$ ), were recorded during the training sessions. These parameters that reflect the sensitivities of sensory and motor systems did not differ between treatment groups (Table 1). To assess the state of arousal and activity, the inter-trial crossings and the total numbers of conditioned reactions, i.e., hurdle crossings in response to CS+ and CS- presentations, were counted. Additionally, as the discrimination deficit of ANI-treated gerbils was most pronounced during the first part of a given training session, the hurdle crossings performed during 3 min of habituation immediately preceding each training session were monitored. Compared with saline-treated controls, injections of ANI caused no significant changes in any of these parameters (Table 1). Thus, neither the drug per se nor an inhibition of cerebral protein synthesis caused alterations in the state of arousal and activity or deficits in sensory transduction and motor systems that could account for the learning deficits. Moreover, compared to the initial day of training, ANI-treated gerbils as well as saline-treated gerbils showed decreasing exploratory activities and increasing numbers of conditioned reactions over days (Table 1). These changes might reflect an increasing familiarity with the training chamber and the experimental procedure, probably indicating that, irrespective of treatment, these gerbils were able to remember the experimental situation.

Taken together, these findings indicate that gerbils injected with $113 \mathrm{mM}$ ANI after the initial session of FM discrimination training showed a decrement in discrimination performance during subsequent training performed on three successive days. ANI-treated gerbils improved their discrimination rates within the sessions but started each of the sessions at low levels. In contrast, saline-treated controls improved their discrimination performance between the sessions. Additional parameters suggest that ANI did not cause effects on the state of arousal and activity or on sensory and motor systems that could account for the decrement in discrimination performance.

To control for effects of ANI apart from those caused by protein-synthesis inhibition, a $0.04 \mathrm{mM}$ solution of ANI was bilaterally infused into the auditory cortex of gerbils

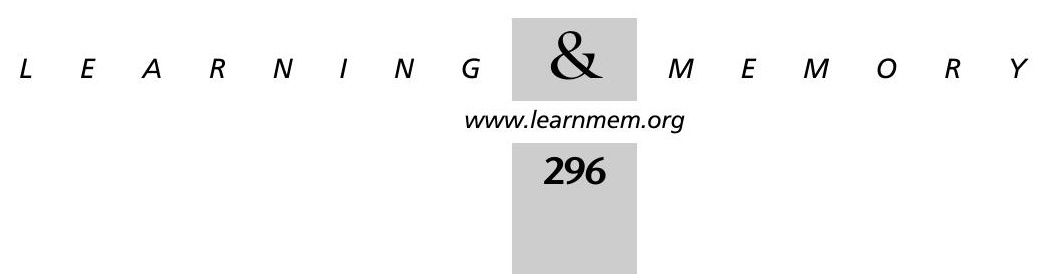


Table 1. Data recorded during 3 min of habituation to the shuttle box and during the sessions of FM discrimination training of gerbils injected with saline $(n=10)$ or $113 \mathrm{mM}$ ANI $(n=11)$ after initial training

\begin{tabular}{|c|c|c|c|c|c|c|c|c|}
\hline \multirow{2}{*}{$\begin{array}{l}\text { Treatment } \\
\text { group }\end{array}$} & \multirow[b]{2}{*}{ Session } & \multirow{2}{*}{$\begin{array}{l}\text { Number of } \\
\text { crossings } \\
\text { during } \\
\text { habituation }\end{array}$} & \multicolumn{3}{|c|}{ Number of conditioned reactions } & \multirow{2}{*}{$\begin{array}{l}\text { Number of } \\
\text { inter-trial } \\
\text { crossings }\end{array}$} & \multirow{2}{*}{$\begin{array}{c}\text { Shock } \\
\text { intensities } \\
{[\mathrm{mA}]}\end{array}$} & \multirow{2}{*}{$\begin{array}{c}\text { Avoidance } \\
\text { times } \\
\text { [sec] }\end{array}$} \\
\hline & & & $\mathrm{CR}+$ & $\mathrm{CR}-$ & Total & & & \\
\hline \multirow[t]{4}{*}{ Saline } & 1 & $8.30 \pm 1.54$ & $1.50 \pm 0.52$ & $1.70 \pm 0.47$ & $3.20 \pm 0.87$ & $2.10 \pm 0.60$ & $0.35 \pm 0.04$ & $3.90 \pm 0.23$ \\
\hline & 2 & $3.90 \pm 1.09$ & $7.10 \pm 1.63$ & $4.30 \pm 0.79$ & $11.40 \pm 2.37$ & $2.80 \pm 0.68$ & $0.33 \pm 0.03$ & $3.73 \pm 0.22$ \\
\hline & 3 & $3.00 \pm 0.75$ & $8.30 \pm 1.32$ & $3.70 \pm 0.79$ & $12.00 \pm 1.94$ & $1.40 \pm 0.43$ & $0.34 \pm 0.03$ & $3.04 \pm 0.16$ \\
\hline & 4 & $1.70 \pm 0.37$ & $11.80 \pm 1.28$ & $4.80 \pm 0.70$ & $16.60 \pm 1.38$ & $2.00 \pm 0.84$ & $0.34 \pm 0.03$ & $3.31 \pm 0.11$ \\
\hline \multirow[t]{4}{*}{$\mathrm{ANI}$} & 1 & $8.45 \pm 1.22$ & $2.18 \pm 0.48$ & $2.00 \pm 0.69$ & $4.18 \pm 0.92$ & $2.45 \pm 0.74$ & $0.33 \pm 0.05$ & $3.59 \pm 0.54$ \\
\hline & 2 & $4.36 \pm 0.69$ & $4.09 \pm 1.11$ & $3.55 \pm 1.00$ & $7.64 \pm 1.92$ & $2.55 \pm 0.67$ & $0.33 \pm 0.03$ & $3.51 \pm 0.32$ \\
\hline & 3 & $2.00 \pm 0.45$ & $7.09 \pm 1.30$ & $4.27 \pm 0.83$ & $11.36 \pm 2.07$ & $1.36 \pm 0.47$ & $0.32 \pm 0.03$ & $3.91 \pm 0.13$ \\
\hline & 4 & $2.27 \pm 0.45$ & $8.09 \pm 2.11$ & $5.18 \pm 0.95$ & $13.27 \pm 2.84$ & $2.45 \pm 0.68$ & $0.33 \pm 0.02$ & $3.73 \pm 0.21$ \\
\hline
\end{tabular}

ANOVA

Main effect of treatment

$$
\begin{gathered}
F<1 \\
F_{(3,57)}=24.38 \\
P<0.001
\end{gathered}
$$

$F_{(1,19)}=2.92$

$F<1$

$F_{(1,19)}=1.29$

$F<1$

$F<1$

$F^{*}<1$

Main effect of session

$F<1$

$F_{(3,57)}=14.79$
$P<0.001$

$F_{(3,57)}=6.39$
$P<0.001$

$F_{(3,57)}=14.41 \quad F_{(3,57)}=1.32$

$F<1$

$F^{*}<1$

Treatment $\mathrm{x}$ session

$F_{(3,57)}=1.21$

$F<1$

$F<1$

$F<1$

$F<1 \quad F_{(3,33)}{ }^{*}=2.19$

Data were collected during the experiment shown in Fig. 2. Gerbils were exposed to the shuttle box for 3 min before each of the training sessions to equilibrate to the experimental environment. During these habituation periods, the numbers of hurdle crossings were recorded. During the subsequent FM discrimination training, the correct conditioned responses $(\mathrm{CR}+)$, false alarms (CR-), inter-trial crossings, footshock intensities, and avoidance times were monitored. The total numbers of conditioned reactions were calculated as the sum of CR+ and CR-. *Missing values due to gerbils that failed to perform at least one CR+ per session.

twice: immediately after and $2 \mathrm{~h}$ after completion of the initial training session. This dose was shown to cause only a non-significant inhibition of protein synthesis following injection into rat hippocampus (Barea-Rodriguez et al. 2000). In contrast to injections of $113 \mathrm{mM}$ ANI, administrations of $0.04 \mathrm{mM}$ ANI to the gerbil auditory cortex did not affect FM discrimination learning during the subsequent three days of training ( $D$ of session 1 to session $4,0.04 \mathrm{mM}$ ANI: $5.50 \pm 1.26,12.17 \pm 1.54,14.00 \pm 2.27,15.17 \pm 1.58$; $D$ of session 1 to session 4 , saline: $0.50 \pm 1.28,10.67 \pm 2.88$, $10.50 \pm 1.61,15.50 \pm 2.92$; means \pm s.e.m., $\mathrm{n}=6$ per group). ANOVA revealed no significant main effect of treatment $\left(F_{(1,10)}=3.03\right)$, a significant main effect of session $\left(F_{(3,30)}=15.69 ; P<0.001\right)$, and no significant interaction between both $(F<1)$.

\section{Effects of Protein-Synthesis Inhibitors Injected After Repeated Training}

For the assessment of potential effects of ANI on the behavioral expression and on processes involved in retention, retrieval, and reconsolidation of an established FM discrimination reaction, gerbils were trained every $24 \mathrm{~h}$ to reach an asymptotic level of discrimination performance. Surgery was performed after session 9, and saline or $113 \mathrm{mM} \mathrm{ANI}$ were injected after session 10. Figure $3 \mathrm{~A}$ compares the discrimination rates of sessions 8 to 13 between treatment groups. ANOVA revealed neither significant main effects of treatment $(F<1)$ and session $\left(F_{(5,20)}=1.14\right)$ nor a significant interaction between both $(F<1)$. Thus, post-session injections of ANI into the auditory cortex of well-trained gerbils did not affect the performance of the established FM discrimination reaction during subsequent days of training. The higher variations in the discrimination rates monitored during session 10 probably reflect an effect of surgery.

Next, the effect of ANI on processes involved in the addition of new information to existing stores was assessed. For this purpose, gerbils were trained on the FM discrimination task daily for a total of $11 \mathrm{~d}$ (Fig. 3B). Surgery was performed after session 6 and saline or a $66 \mathrm{mM}$ solution of ANI was administered after completion of session 7 , i.e., when the discrimination rate, on average, exceeded the level of $30 \%$. At this stage of training the discrimination reaction was only partially established and therefore still improvable by additional training. ANOVA comparing $D$ over sessions 7 to 11 across treatments revealed significant main effects of treatment $\left(F_{(1,10)}=6.66, P<0.05\right)$ and session $\left(F_{(4,40)}=3.94, P<0.01\right)$, and no significant treatment $\mathrm{x}$ session interaction $\left(F_{(4,40)}=1.24\right)$. Thus ANI-treated gerbils as well as controls were able to improve their discrimination performance over sessions. This improvement, however, was delayed in ANI-treated gerbils when compared with saline-treated controls. Planned examinations revealed significant group differences in $D$ in sessions $8\left(t_{(10)}=2.45\right.$, $P<0.05)$ and $9\left(t_{(10)}=2.74, P<0.025\right)$, but no longer in

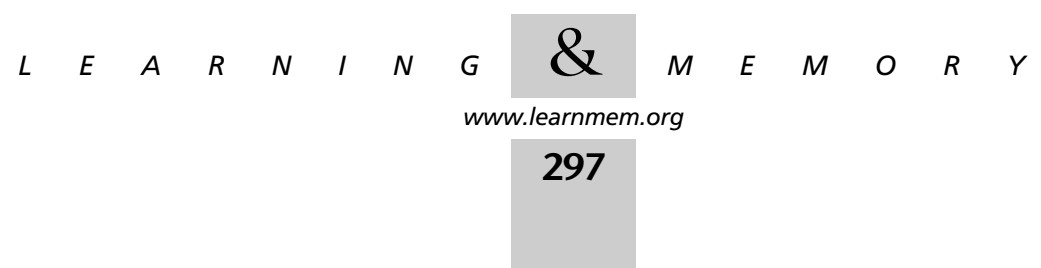



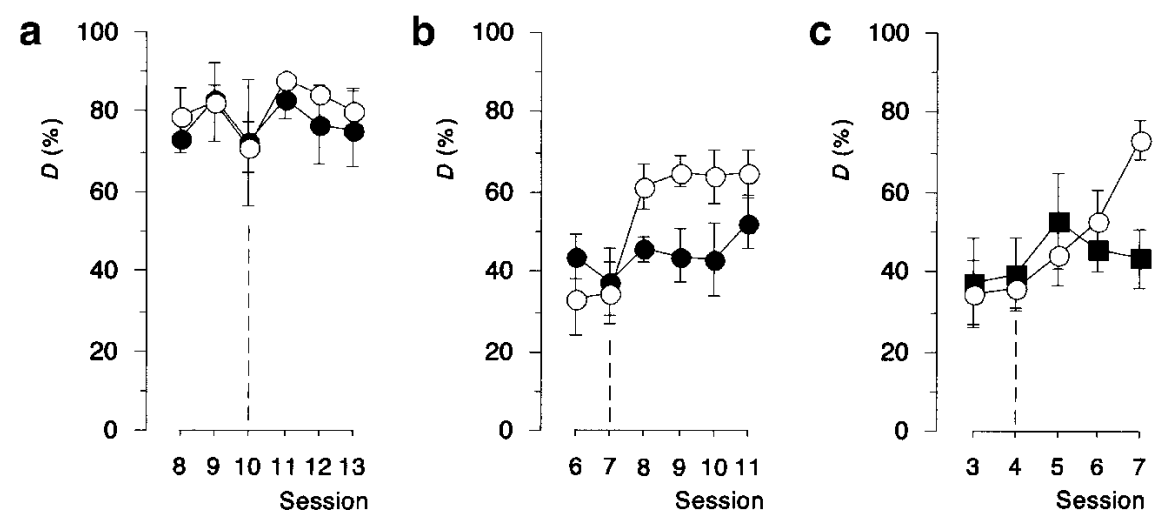

tion, retrieval, and reconsolidation of the established reaction were affected.

Figure 3 Protein-synthesis inhibitors impaired the improvement but not the expression of a partially established frequency-modulated tone (FM) discrimination reaction. Gerbils were trained on the FM discrimination task every $24 \mathrm{~h}$. Bilateral injections of saline or drugs were performed twice, immediately and $2 \mathrm{~h}$ after completion of the sessions indicated by dashed lines. (a) Gerbils trained up to the asymptotic level of FM discrimination performance were injected with saline (open circles, $n=3$ ) or $113 \mathrm{mM}$ protein-synthesis inhibitor anisomycin (ANI) (filled circles, $n=3$ ). (b) Gerbils with a partially established FM discrimination reaction were injected with saline (open circles, $n=6$ ) or $66 \mathrm{mM}$ ANI (filled circles, $n=6$ ). (c) Gerbils with a partially established FM discrimination reaction were injected with saline (open circles, $n=9$ ) or $15 \mathrm{mM}$ protein-synthesis inhibitor emetine (EME) (filled rectangles, $n=7$ ). Panels a to $c$ represent data obtained from different sets of animals. All data points represent group means \pm S.E.M.

session $10\left(t_{(10)}=1.86, P>0.05\right)$. On day 11 , the discrimination scores of ANI-treated gerbils nearly reached the level of controls $\left(t_{(10)}=1.34, P>0.2\right)$. When compared with the pre-injection level, administration of ANI did not impair the performance of the established discrimination reaction.

To confirm that the effect of ANI on FM discrimination learning was caused by protein-synthesis inhibition, another inhibitor of translation, EME, was bilaterally applied to the auditory cortex of repeatedly trained gerbils after completion of session 4, i.e., when the discrimination reaction was partially established and the discrimination rate, on average, exceeded the level of $30 \%$. ANOVA comparing $D$ over sessions 4 to 7 across treatment groups revealed no significant main effect of treatment $(F<1)$, a significant main effect of session $\left(F_{(3,42)}=2.96, P<0.05\right)$, and a significant treatment $\mathrm{x}$ session interaction $\left(F_{(3,42)}=3.04, P<0.05\right)$. The interaction plot shown in Figure $3 \mathrm{C}$ indicates that saline-treated but not EME-treated gerbils were able to improve their performance over sessions. Accordingly, ANOVA of $D$ within each of the treatment groups revealed a main effect of session within the vehicle-treated group $\left(F_{(3,24)}=5.24, P\right.$ $<0.01)$ but not within the EME-treated group $(F<1)$.

Taken together, post-session administrations of two unrelated protein-synthesis inhibitors to the auditory cortex of repeatedly trained gerbils impaired the improvement of a partially established FM discrimination reaction as measured during subsequent training sessions in saline-treated controls. When compared with the pre-injection level, the performance of the task was normal, implying that neither sensory and motor systems required for performance of the discriminative behavior nor mechanisms involved in retentreatment groups revealed no main effect of treatment $(F$ $<1$, a significant main effect of session $\left(F_{(2,18)}=6.27 ; P\right.$ $<0.01)$, and no treatment $\mathrm{x}$ session interaction $(F<1)$. Similarly, injections of EME three days before the initial training had no significant effects on FM discrimination learning (Fig. 4B). ANOVA comparing $D$ over sessions across treatments revealed no main effect of treatment $(F<1)$, a main effect of session $\left(F_{(1,6)}=6.92, P<0.05\right)$, and no treatment $\mathrm{x}$ session interaction $(F<1)$. These findings indicate that
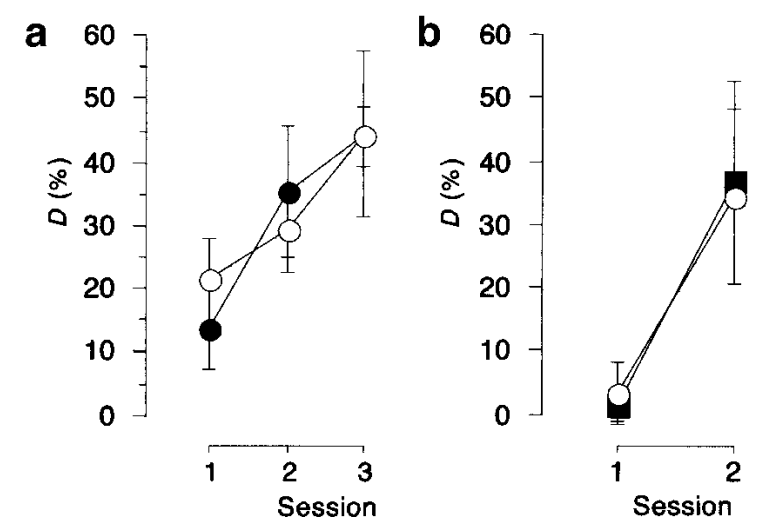

Figure 4 Administration of protein-synthesis inhibitors several days before initial training did not affect frequency-modulated tone (FM) discrimination learning. Gerbils were trained on the FM discrimination task every 24 h. (a) Saline (open circles, $n=5$ ) or 113 $\mathrm{mM}$ protein-synthesis inhibitor anisomycin (ANI) (filled circles, $n=6$ ) were bilaterally injected twice $48 \mathrm{~h}$ and $46 \mathrm{~h}$ before the initial training. (b) Saline (open circles, $n=3$ ) or $15 \mathrm{mM}$ proteinsynthesis inhibitor emetine (EME) (filled rectangles, $n=5$ ) were bilaterally injected twice $72 \mathrm{~h}$ and $70 \mathrm{~h}$ before the initial training. All data points represent group means \pm S.E.M.

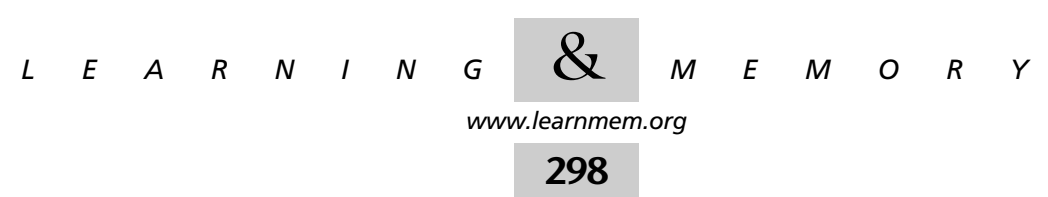


neither the drugs per se nor an inhibition of cerebral protein synthesis exerts long-term toxic effects that could account for the discrimination deficit observed when the inhibitors were given during the post-acquisition phase.

\section{DISCUSSION}

Using a pharmacological approach, we addressed the question of the functional relevance of cerebral protein synthesis in the Mongolian gerbil for learning the discrimination of the directions of modulation of FM. In relation to salinetreated controls, bilateral injections of the protein-synthesis inhibitor ANI into the primary auditory cortex and its adjacent fields after FM discrimination training led to discrimination deficits measured in daily training sessions performed for up to three successive days. Evaluation of blocks of trials revealed that ANI-treated gerbils markedly improved their discrimination rates within the training sessions but started each session again at low performance levels. In contrast, saline-treated gerbils showed on average higher discrimination rates at the beginning of a given training session than at the end of the preceding one. When gerbils were repeatedly trained to reach a certain level of discrimination performance before post-session injections of ANI, the improvement, but not the expression, of the partially established discrimination reaction was impaired during subsequent training. Intracortical injections of EME, another inhibitor of translation, confirmed this finding. Neither ANI nor EME affected FM discrimination learning when administered several days before the initial training.

A comprehensive set of behavioral data was collected to control for unspecific effects of pharmacological treatment. Firstly, as recorded on subsequent training days, gerbils injected with saline after the initial training showed FM discrimination rates very similar to those monitored in untreated gerbils (data not shown), indicating that treatments and procedures required for drug delivery, i.e., surgery, injection, and anesthesia, caused no impairments in FM discrimination learning and performance. These findings support a previous report demonstrating that, in rodents, halothane anesthesia causes no retrograde amnesia and an anterograde amnesia only when applied within $2 \mathrm{~h}$ before a learning experiment (Rosman et al. 1992). Secondly, previous studies on Mongolian gerbils have shown that either bilateral or right auditory cortex lesions impair the discrimination of FM (Wetzel et al. 1998; Ohl et al. 1999). In the present study, a discrimination deficit was evident only after bilateral drug administrations. Post-training unilateral injections of $113 \mathrm{mM}$ ANI into the right auditory cortex twice, immediately and $2 \mathrm{~h}$ after initial training, did not impair FM discrimination learning as measured on subsequent training days (data not shown), suggesting that drug treatment caused no functional damage to this brain structure. Thirdly, FM discrimination learning was normal when ANI or EME was applied several days before initial training (Fig.
4) and, finally, post-session injections of the inhibitors to repeatedly trained animals did not affect performance of an established FM discrimination reaction on subsequent days (Fig. 3). Together these findings imply that neither the procedures of surgery and injection, nor the drugs per se, caused long-term effects on mechanisms involved in acquisition, retention, retrieval, and expression of the discrimination reaction that could account for the amnesic effect. Moreover, the results indicate that, as previously shown for other species and learning paradigms (Davis and Squire 1984; Stork and Welzl 1999), administration of the proteinsynthesis inhibitors in a narrow temporal relation to the learning experiment is also required for their amnesic actions on FM discrimination learning in the gerbil to occur.

ANI was shown previously to interfere with the activity of certain protein kinases even at doses that did not inhibit protein synthesis (Edwards and Mahadevan 1992; Hazzalin et al. 1998). Therefore, the effect of ANI on FM discrimination learning observed in the present study could be attributable to nonselective actions on the physiology of cortical neurons. However, the discrimination deficit was monitored after intracortical injections of $113 \mathrm{mM}$ or $66 \mathrm{mM}$ solutions of ANI, whereas administrations of a $0.04 \mathrm{mM}$ solution of ANI were ineffective. In rat hippocampus, application of $1 \mu 1$ of a $10 \mathrm{mM}$ solution of ANI has been shown to cause more than $80 \%$ inhibition of protein synthesis, whereas a $0.04 \mathrm{mM}$ solution had only a marginal effect (Barea-Rodriguez et al. 2000). Therefore, the amnesic action of ANI monitored in the present study was dose-dependent and occurred with dosages that, as deduced from literature data, should induce more than $80 \%$ inhibition of protein synthesis in the target region. Moreover, administration of another protein-synthesis inhibitor, EME, impaired FM discrimination learning in a manner similar to that of ANI. The two drugs have the same primary action, i.e., inhibition of protein synthesis, but a different spectrum of side effects. The finding that they both act on FM discrimination learning increases the confidence that the observed effect is attributable to their common primary action.

Changes in an animal's behavior measured in re-learning sessions some time after initial learning may reflect effects on many processes, including performance, acquisition, consolidation, retention, and retrieval of memory (Abel and Lattal 2001; Cahill et al. 2001). To look for side effects of ANI on mechanisms that may interfere with the learning performance, general parameters (such as exploratory activities, inter-trial crossings, avoidance times, and footshock intensities) were monitored during the behavioral experiments (Table 1). None of these parameters was significantly changed in comparison to saline-treated gerbils, indicating that the drug did not cause alterations in the state of arousal and activity or in the sensitivities of sensory and motor systems that could account for the learning deficits.

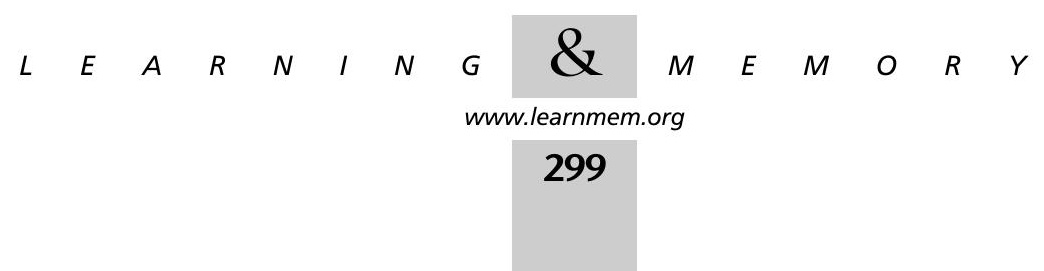


Gerbils that received injections of ANI after the first training session showed a marked improvement in the discrimination rates between the initial and the final blocks of trials of subsequent training sessions (Fig. 2B,C). Consequently, the discrimination rates of this group monitored during the final block of trials of the post-injection training sessions did not significantly differ from the level of controls, indicating that ANI-treated gerbils were still able to perform the sensory processing required for discriminating FM as well as the sensorimotor integration and behavior necessary to demonstrate the discrimination reaction. However, these same animals failed to perfom well during the initial trials of the post-injection training sessions. The resulting mean discrimination rate in block A of ANI-treated gerbils was near zero and differed significantly from the level in controls, implying that much of the previously learned information was lost during the inter-session intervals in which the animals were not exposed to the maze. Therefore, these findings suggest that, in the gerbil, mechanisms that support learning and memory-related aspects of FM processing are sensitive to protein-synthesis inhibitors applied to the auditory cortex shortly after training. The results can be explained by postulating that inhibition of protein synthesis in the gerbil auditory cortex during the post-acquisition phase causes a deficit in the consolidation of FM discrimination memory, that is, in a progressive stabilization of the newly acquired memory trace and in processes that ensure its retrieval. In this sense, the increase in performance observed within each of the post-injection training sessions might be indicative either of a recovery during the course of the session from a retrieval failure, or of the unimpaired capabilities of acquiring the discrimination reaction and of forming a short-term memory for it, thus of re-learning the discrimination reaction on a daily basis.

Because neither ANI nor EME impaired the expression of a previously established FM discrimination reaction (Fig. 3 ), the amnesic action of the protein-synthesis inhibitors cannot be explained as an effect on the general abilities to retain and retrieve the information. Moreover, in contrast to some suggestions in relation to other species, brain structures, and learning paradigms (Nader et al. 2000; Sara 2000), the present findings, consistent with other studies (Berman and Dudai 2001; Lattal and Abel 2001; Taubenfeld et al. 2001; Vianna et al. 2001), do not lend support to a general view that memory retrieval activates reconsolidation processes that are susceptible to protein-synthesis inhibitorinduced amnesia. However, the inhibitors exerted a decrement in the improvement of a partially established FM discrimination reaction. As this decrement was comparable in extent to that observed after original learning, initial acquisition of the discrimination reaction and the addition of information to pre-existing stores may recruit common mechanisms of consolidation.
Gerbils treated with ANI showed some improvement over training days (Fig. 2A,B) and were able to reach discrimination rates similar to those of control-injected animals at four days post-injection (Fig. 3B), indicating that longterm memory retention and/or retrieval were not completely and irreversibly blocked. However, compared with saline-treated controls, a discrimination deficit was evident in drug-treated gerbils for several training days. The exact reasons for this finding are currently not clear. Effects of ANI topically applied to distinct brain regions on learningrelated behavior during two or more successive days have recently been observed in some species and paradigms, for example, in a classical conditioning of rabbits and in the extinction of a fear-motivated response of rats (Bracha et al. 1998; Vianna et al. 2001), but not in others, such as the extinction of a conditioned taste aversion in rats (Berman and Dudai 2001). This implies that the long-term effect of ANI application may be specific to the task, species, and/or brain structure under investigation.

The present results led to the assumption that, during the post-acquisition phase, some type of protein-synthesisdependent trace is produced that either sensitizes relevant local nodes (e.g., neurons, synapses) for future use or modifies them for later processes of consolidation required for stabilization and/or retrieval of long-term memory. The finding that the discrimination scores of controls observed during the first block of trials of a re-training session were increased over those in the final block of the preceding session (Fig. 2B,D) would support this assumption. Experimental evidence suggests the importance of such mechanisms for plasticity-related processes in the nervous system of invertebrates and vertebrates (Frey and Morris 1997; Casadio et al. 1999; Quevedo et al. 1999). Whether similar mechanisms contribute to the long-lasting effect of proteinsynthesis inhibition observed in the present study is subject of future investigations. Interestingly, as published during the reviewing of this manuscript, learning-induced tuning plasticity in the auditory cortex of the guinea pig may exhibit long-term consolidation, attaining asymptote at $3 \mathrm{~d}$ (Galvan and Weinberger 2002).

In summary, the present results indicate that application of protein-synthesis inhibitors to the auditory cortex of gerbils during the post-acquisition phase interfered with long-term FM discrimination memory for a number of subsequent training days, while leaving short-term memory intact. Control experiments imply that this effect was likely due to impaired memory consolidation. Future studies are required to test hypotheses that account for these observations.

\section{MATERIALS AND METHODS}

\section{Animals}

Seventy-seven adult male Mongolian gerbils (Meriones unguicula$t u s$ ) were used for the experiments. The animals were housed in

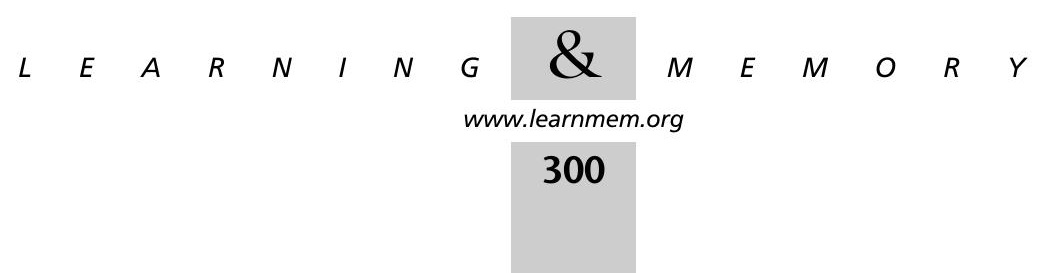


groups of five and given free access to standard laboratory chow and tap water on a 12-h light/dark cycle (light on at 6 a.m.).

All experiments were approved by the animal care committee of Sachsen-Anhalt (No. 53b-42502/2-111/150; IfN MD) in accordance with the NIH Guide for the Care \& Use of Laboratory Animals (NIH, 1996).

\section{Surgical Procedures and Intracortical Injections}

The procedures of surgery and intracortical injection have previously been described in detail (Richter et al. 1999; Budinger et al. $2000 \mathrm{~b})$. In brief, gerbils were deeply anesthetized $(0.4 \mathrm{mg}$ ketamine and $0.3 \mathrm{mg}$ xylacine per $100 \mathrm{~g}$ body weight, i.p.). The cranial skin was disinfected and incised and three holes of about $1 \mathrm{~mm}$ in diameter were bilaterally drilled into the skull at locations covering the primary, anterior, and posterior fields of the auditory cortex (for coordinates, see Budinger et al. 2000b). After approximately 20 $\mathrm{h}$ of recovery, intracortical injections were performed under light halothane anesthesia using glass micropipettes mounted on a nanoinjector (WPI). Per target region, $1 \mu \mathrm{l}$ of either anisomycin (Sigma; $0.04 \mathrm{mM}=0.01 \mu \mathrm{g} / \mu \mathrm{l}, 66 \mathrm{mM}=18 \mu \mathrm{g} / \mu \mathrm{l}$, or $113 \mathrm{mM}=30$ $\mu \mathrm{g} / \mu \mathrm{l}$ ), or emetine (Sigma; $15 \mathrm{mM}=8 \mu \mathrm{g} / \mu \mathrm{l})$, or vehicle $(0.9 \%$ saline) were injected over a period of $4 \mathrm{~min}$. Injections were repeated after an interval of $2 \mathrm{~h}$. All injections were administered to all three sites every time an injection was performed. All solutions used for intracortical injections were adjusted to $\mathrm{pH} 7$.

The dosages used in the present study were deduced from literature data showing that ANI and EME efficiently inhibit protein synthesis in various species and brain structures (for references, see Introduction) and that a level of $80 \%$ protein-synthesis inhibition is critical for amnesic effects to occur (Flood et al. 1973; Quinton and Kramarcy 1977). Specifically, the highest dose (113 mM) of ANI was chosen based on previously published studies showing $80 \%$ suppression of protein synthesis in rat cerebral cortex and hippocampus after injections of $100 \mu \mathrm{g}$ ANI per hemisphere (Rosenblum et al. 1993; Meiri and Rosenblum 1998). During the course of our experiments, data were published showing that even lower doses of ANI are sufficient to induce $>\mathbf{8 0} \%$ suppression of protein synthesis in rat hippocampus (Barea-Rodriguez et al. 2000). Therefore, in subsequent experiments the dose of ANI was reduced to $66 \mathrm{mM}$ as indicated. To control for amnesic effects of ANI apart from those caused by protein-synthesis inhibition, the lowest dose $(0.04 \mathrm{mM})$ was used. This dose was shown to induce only a nonsignificant inhibition of protein synthesis following injection into rat hippocampus (Barea-Rodriguez et al. 2000). The dose of EME was chosen based on previous studies on chicks showing a highly localized inhibition of protein synthesis after intracranial injections (Patterson et al. 1986).

\section{Behavioral Experiments}

Gerbils were trained in daily sessions to discriminate the directions of modulation of linearly frequency-modulated tones as described earlier (Ohl et al. 1999). In brief, behavioral experiments were performed in a shuttle box (E10-15, Coulbourn Instruments) consisting of two compartments separated by a $3 \mathrm{~cm}$-high hurdle. Before each of the training sessions, gerbils were allowed to habituate for $3 \mathrm{~min}$ to the experimental situation in the shuttle box without acoustical stimulation and footshock. During training, conditioned stimuli consisting of FM of 1-2 kHz ascending frequency (CS+) or $2-1 \mathrm{kHz}$ descending frequency (CS-) were presented in a pseudorandomized order. Animals were required to perform a hurdle crossing when presented with CS+ and to suppress this response when presented with CS-. Hurdle crossings occurring within 6 sec of the onset of $\mathrm{CS}+$ were regarded as correct conditioned responses $(\mathrm{CR}+)$. If, during $\mathrm{CS}+$ presentation, a response did not occur within $6 \mathrm{sec}$, the gerbil was punished by footshock of 200-500 $\mu \mathrm{A}$ through the grid floor. The footshock lasted for up to $4 \mathrm{sec}$ and could be terminated by the gerbil by crossing the hurdle. Footshock intensities required to cause the gerbils to cross the hurdle were individually adjusted, starting with $250 \mu \mathrm{A}$, during the first footshock presentations of each training session. Hurdle crossings occurring within $6 \mathrm{sec}$ of the onset of CS- were regarded as false alarms (CR-) and punished by a footshock of $300 \mu \mathrm{A}$ for $1 \mathrm{sec}$. A training session consisted of 60 trials, that is, 30 presentations of each CS+ and CS-. The inter-trial interval was pseudorandomly varied (mean $=15 \mathrm{sec}$, range $=12-18 \mathrm{sec}$ )

\section{Analysis of Behavioral Data}

Relative frequencies of $\mathrm{CR}+$ and of $\mathrm{CR}$ - were calculated as the number of CR+ expressed as percent of trials with CS+ presentations, and the number of CR- expressed as percent of trials with CS- presentations, respectively. The discrimination performance was quantified by the measure $D[\%]$, i.e., the difference between the relative frequencies of $\mathrm{CR}+$ and $\mathrm{CR}-. D$ was estimated for each animal and session. Where indicated, $D$ was additionally calculated for blocks representing the initial (block A) and the final (block B) parts of a session. To ensure equal numbers of CS+ and CS- presentations within each of the blocks, block A consisted of 24 trials and block B consisted of 36 trials. To assess drug effects on arousal and activity, the numbers of hurdle crossings during the habituation period preceding each training session as well as the inter-trial activity, i.e., the numbers of hurdle crossings occurring during the inter-trial intervals, were monitored. To assess drug effects on sensory systems and motor coordination, footshock intensities required to cause the gerbils to cross the hurdle and avoidance times, i.e., the times required to change the compartment during $\mathrm{CR}+$, were recorded within the training sessions

All data are expressed as group means \pm S.E.M. Statistical evaluation was performed using a repeated measures ANOVA (StatView 5.0.1, SAS). Planned examinations, i.e., comparisons of individual data points, were performed using Student's two-tailed $t$-test for paired or unpaired comparisons where appropriate. $P$ values of $<0.05$ were considered as statistically significant.

\section{ACKNOWLEDGMENTS}

We are grateful to Lydia Löw for excellent technical assistance and to Henning Scheich and Eckart D. Gundelfinger for helpful discussions. This work was supported by the Land Sachsen-Anhalt and the European Community (ESF).

The publication costs of this article were defrayed in part by payment of page charges. This article must therefore be hereby marked "advertisement" in accordance with 18 USC section 1734 solely to indicate this fact.

\section{REFERENCES}

Abel, T. and Lattal, K.M. 2001. Molecular mechanisms of memory acquisition, consolidation and retrieval. Curr. Opin. Neurobiol. 11: $180-187$.

Aitkin, L. 1990. The auditory cortex. Chapman and Hall, London, UK

Alkon, D.L. 1998. Molecular specificity of synaptic changes responsible for associative memory. Adv. Exp. Med. Biol. 446: 1-15.

Alkon, D.L., Amaral, D.G., Bear, M.F., Black, J., Carew, T.J., Cohen, N.J., Disterhoft, J.F., Eichenbaum, H., Golski, S., Gorman, L.K. et al. 1991.

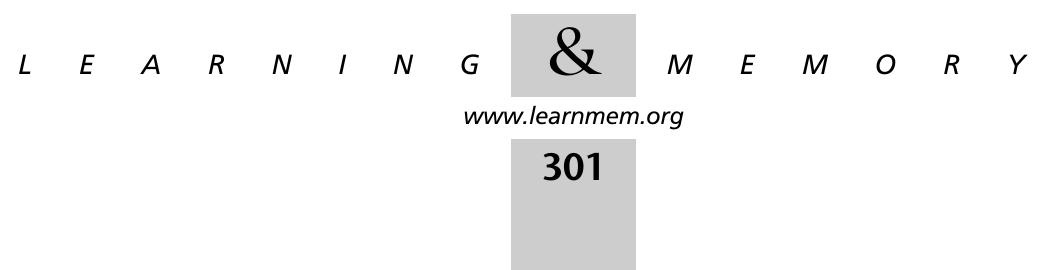


Learning and memory. FESN Study Group. Brain Res. Rev 16: $193-220$

Armstrong, R.C. and Montminy, M.R. 1993. Transsynaptic control of gene expression. Annu. Rev. Neurosci. 16: 17-29.

Bailey, C.H., Bartsch, D., and Kandel, E.R. 1996. Toward a molecular definition of long-term memory storage. Proc. Natl. Acad. Sci. U.S.A 93: $13445-13452$.

Bakin, J.S. and Weinberger, N.M. 1990. Classical conditioning induces CS-specific receptive field plasticity in the auditory cortex of the guinea pig. Brain Res. 536: 271-286.

Barea-Rodriguez, E.J., Rivera, D.T., Jaffe, D.B., and Martinez, J.L., Jr. 2000. Protein synthesis inhibition blocks the induction of mossy fiber long-term potentiation in vivo. J. Neurosci. 20: 8528-8532.

Berman, D.E. and Dudai, Y. 2001. Memory extinction, learning anew, and learning the new: dissociations in the molecular machinery of learning in cortex. Science 291: 2417-2419.

Bracha, V., Irwin, K.B., Webster, M.L., Wunderlich, D.A., Stachowiak, M.K. and Bloedel, J.R. 1998. Microinjections of anisomycin into the intermediate cerebellum during learning affect the acquisition of classically conditioned responses in the rabbit. Brain Res. 788: $169-178$

Budinger, E., Heil, P. and Scheich, H. 2000a. Functional organization of auditory cortex in the Mongolian gerbil (Meriones unguiculatus). III. Anatomical subdivisions and corticocortical connections. Eur. J. Neurosci. 12: 2425-2451.

Budinger, E., Heil, P., and Scheich, H. 2000b. Functional organization of auditory cortex in the Mongolian gerbil (Meriones unguiculatus). IV. Connections with anatomically characterized subcortical structures. Eur. J. Neurosci. 12: 2452-2474.

Cahill, L., McGaugh, J.L., and Weinberger, N.M. 2001. The neurobiology of learning and memory: Some reminders to remember. Trends Neurosci. 24: 578-581.

Carew, T.J. 1996. Molecular enhancement of memory formation. Neuron 16: 5-8.

Casadio, A., Martin, K.C., Giustetto, M., Zhu, H., Chen, M., Bartsch, D., Bailey, C.H., and Kandel, E.R. 1999. A transient, neuron-wide form of CREB-mediated long-term facilitation can be stabilized at specific synapses by local protein synthesis. Cell 99: 221-237.

Davis, H.P. and Squire, L.R. 1984. Protein synthesis and memory: A review. Psychol. Bull. 96: 518-559.

DeZazzo, J. and Tully, T. 1995. Dissection of memory formation: From behavioral pharmacology to molecular genetics. Trends Neurosci. 18: $212-218$.

Dudai, Y. 1996. Consolidation: Fragility on the road to the engram. Neuron 17: 367-370.

Edeline, J.M. 1999. Learning-induced physiological plasticity in the thalamo-cortical sensory systems: A critical evaluation of receptive field plasticity, map changes and their potential mechanisms. Prog. Neurobiol. 57: 165-224.

Edwards, D.R. and Mahadevan, L.C. 1992. Protein synthesis inhibitors differentially superinduce c-fos and c-jun by three distinct mechanisms: Lack of evidence for labile repressors. EMBO J. 11: 2415-2424.

Ehret, G. 1997. The auditory cortex. J. Comp. Physiol. [A] 181: 547-557.

Flood, J.F., Rosenzweig, M.R., Bennett, E.L., and Orme, A.E. 1973. The influence of duration of protein synthesis inhibition on memory Physiol. Behav. 10: 555-562.

Frey, U. and Morris, R.G. 1997. Synaptic tagging and long-term potentiation. Nature 385: 533-536.

Galvan, V.V. and Weinberger, N.M. 2002. Long-term consolidation and retention of learning-induced tuning plasticity in the auditory cortex of the guinea pig. Neurobiol. Learn. Mem. 77: 78-108.

Goelet, P., Castellucci, V.F., Schacher, S., and Kandel, E.R. 1986. The long and the short of long-term memory-a molecular framework. Nature 322: 419-422.

Hazzalin, C.A., Le Panse, R., Cano, E., and Mahadevan, L.C. 1998. Anisomycin selectively desensitizes signalling components involved in stress kinase activation and fos and jun induction. Mol. Cell. Biol. 18: $1844-1854$.
Izquierdo, I. and McGaugh, J.L. 2000. Behavioural pharmacology and its contribution to the molecular basis of memory consolidation. Behav. Pharmacol. 11: 517-534.

Lamprecht, R. and Dudai, Y. 1996. Transient expression of c-Fos in rat amygdala during training is required for encoding conditioned taste aversion memory. Learn. Mem. 3: 31-41.

Lattal, K.M. and Abel, T. 2001. Different requirements for protein synthesis in acquisition and extinction of spatial preferences and context-evoked fear. J. Neurosci. 21: 5773-5780.

Matthies, H. 1989. In search of cellular mechanisms of memory. Prog. Neurobiol. 32: 277-349.

McGaugh, J.L. 2000. Memory-A century of consolidation. Science 287: $248-251$

Meiri, N. and Rosenblum, K. 1998. Lateral ventricle injection of the protein synthesis inhibitor anisomycin impairs long-term memory in a spatial memory task. Brain Res. 789: 48-55.

Menzel, R. 2001. Searching for the memory trace in a mini-brain, the honeybee. Learn. Mem. 8: 53-62.

Nader, K., Schafe, G.E., and Le Doux, J.E. 2000. Fear memories require protein synthesis in the amygdala for reconsolidation after retrieval. Nature 406: 722-726.

Ng, K.T., Gibbs, M.E., Crowe, S.F., Sedman, G.L., Hua, F., Zhao, W., O'Dowd, B., Rickard, N., Gibbs, C.L., Sykova, E. et al. 1991. Molecular mechanisms of memory formation. Mol. Neurobiol. 5: 333-350.

O'Leary, F.A., Byrne, J.H., and Cleary, L.J. 1995. Long-term structural remodeling in Aplysia sensory neurons requires de novo protein synthesis during a critical time period. J. Neurosci. 15: 3519-3525.

Ohl, F.W. and Scheich, H. 1996. Differential frequency conditioning enhances spectral contrast sensitivity of units in auditory cortex (field Al) of the alert Mongolian gerbil. Eur. J. Neurosci. 8: 1001-1017. . 1997. Learning-induced dynamic receptive field changes in primary auditory cortex of the unanaesthetized Mongolian gerbil. J. Comp. Physiol. [A] 181: 685-696.

Ohl, F.W., Scheich, H., and Freeman, W.J. 2001. Change in pattern of ongoing cortical activity with auditory category learning. Nature 412: $733-736$

Ohl, F.W., Wetzel, W., Wagner, T., Rech, A., and Scheich, H. 1999. Bilateral ablation of auditory cortex in Mongolian gerbil affects discrimination of frequency-modulated tones but not of pure tones. Learn. Mem. 6: 347-362.

Patterson, T.A., Alvarado, M.C., Warner, I.T., Bennett, E.L., and Rosenzweig, M.R. 1986. Memory stages and brain asymmetry in chick learning. Behav. Neurosci. 100: 856-865.

Quevedo, J., Vianna, M.R., Roesler, R., de-Paris, F., Izquierdo, I., and Rose, S.P. 1999. Two time windows of anisomycin-induced amnesia for inhibitory avoidance training in rats: protection from amnesia by pretraining but not pre-exposure to the task apparatus. Learn. Mem. 6: 600-607.

Quinton, E.E. and Kramarcy, N.R. 1977. Memory impairment correlates closely with cycloheximide dose and degree of inhibition of protein synthesis. Brain Res. 131: 184-190.

Ramirez, R.R., Gandhi, C.C., Muzzio, I.A., and Matzel, L.D. 1998. Protein synthesis-dependent memory and neuronal enhancement in Hermissenda are contingent on parameters of training and retention. Learn. Mem. 4: 462-477.

Recanzone, G.H., Schreiner, C.E., and Merzenich, M.M. 1993. Plasticity in the frequency representation of primary auditory cortex following discrimination training in adult owl monkeys. J. Neurosci. 13: 87-103.

Ribeiro, S. and Mello, C.V. 2000. Gene expression and synaptic plasticity in the auditory forebrain of songbirds. Learn. Mem. 7: 235-243.

Richter, K., Hess, A., and Scheich, H. 1999. Functional mapping of transsynaptic effects of local manipulation of inhibition in gerbil auditory cortex. Brain Res. 831: 184-199.

Rose, S.P. 2000. God's organism? The chick as a model system for memory studies. Learn. Mem. 7: 1-17.

Rosenblum, K., Meiri, N., and Dudai, Y. 1993. Taste memory: The role of protein synthesis in gustatory cortex. Behav. Neural. Biol. 59: 49-56.

Rosman, E., Quartermain, D., Pang, R., and Turndorf, H. 1992. Halothane

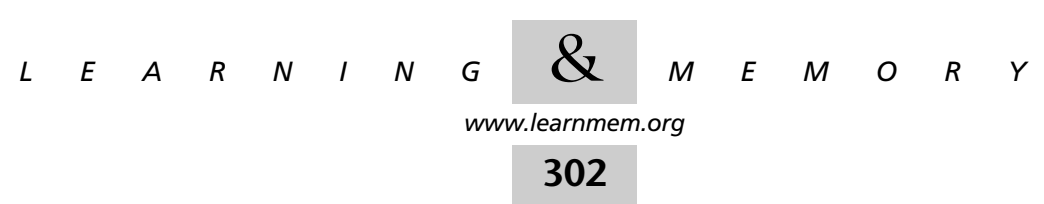


anesthesia causes state-dependent retrieval failure in mice. Physiol. Behav. 52: 449-453.

Sara, S.J. 2000. Retrieval and reconsolidation: Toward a neurobiology of remembering. Learn. Mem. 7: 73-84.

Schafe, G.E., Nader, K., Blair, H.T., and LeDoux, J.E. 2001. Memory consolidation of Pavlovian fear conditioning: A cellular and molecular perspective. Trends Neurosci. 24: 540-546.

Scheich, H. 1991. Auditory cortex: Comparative aspects of maps and plasticity. Curr. Opin. Neurobiol. 1: 236-247.

Scheich, H. and Zuschratter, W. 1995. Mapping of stimulus features and meaning in gerbil auditory cortex with 2-deoxyglucose and c-Fos antibodies. Behav. Brain Res. 66: 195-205.

Scheich, H., Heil, P., and Langner, G. 1993a. Functional organization of auditory cortex in the mongolian gerbil (Meriones unguiculatus). II. Tonotopic 2-deoxyglucose. Eur. J. Neurosci. 5: 898-914.

Scheich, H., Simonis, C., Ohl, F., Tillein, J., and Thomas, H. 1993b. Functional organization and learning-related plasticity in auditory cortex of the Mongolian gerbil. Prog. Brain Res. 97: 135-143.

Scheich, H., Stark, H., Zuschratter, W., Ohl, F.W., and Simonis, C.E. 1997. Some functions of primary auditory cortex in learning and memory formation. Adv. Neurol. 73: 179-193.

Stork, O. and Welzl, H. 1999. Memory formation and the regulation of gene expression. Cell. Mol. Life Sci. 55: 575-592.
Taubenfeld, S.M., Milekic, M.H., Monti, B., and Alberini, C.M. 2001. The consolidation of new but not reactivated memory requires hippocampal C/EBPbeta. Nat. Neurosci. 4: 813-818.

Vianna, M.R., Szapiro, G., McGaugh, J.L., Medina, J.H., and Izquierdo, I. 2001. Retrieval of memory for fear-motivated training initiates extinction requiring protein synthesis in the rat hippocampus. Proc. Natl. Acad. Sci. U.S.A. 98: 12251-12254.

Weiler, I.J., Hawrylak, N., and Greenough, W.T. 1995. Morphogenesis in memory formation: Synaptic and cellular mechanisms. Behav. Brain Res. 66: 1-6.

Weinberger, N.M. 1995. Dynamic regulation of receptive fields and maps in the adult sensory cortex. Annu. Rev. Neurosci. 18: 129-158.

Weinberger, N.M. 1998. Physiological memory in primary auditory cortex: Characteristics and mechanisms. Neurobiol. Learn. Mem. 70: 226-251.

Weinberger, N.M. and Diamond, D.M. 1987. Physiological plasticity in auditory cortex: Rapid induction by learning. Prog. Neurobiol. 29: 1-55.

Wetzel, W., Ohl, F.W., Wagner, T., and Scheich, H. 1998. Right auditory cortex lesion in Mongolian gerbils impairs discrimination of rising and falling frequency-modulated tones. Neurosci. Lett. 252: 115-118.

Received February 11, 2002; accepted in revised form June 28, 2002.

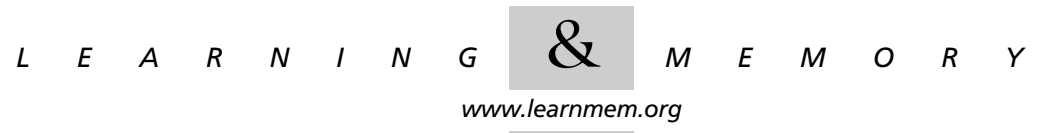




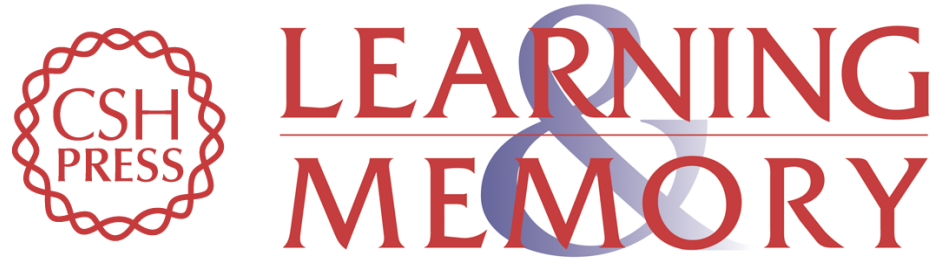

\section{Memory Consolidation for the Discrimination of Frequency-Modulated Tones in Mongolian Gerbils Is Sensitive to Protein-Synthesis Inhibitors Applied to the Auditory Cortex}

Michaela Kraus, Horst Schicknick, Wolfram Wetzel, et al.

Learn. Mem. 2002, 9:

Access the most recent version at doi:10.1101//m.47502

References This article cites 64 articles, 17 of which can be accessed free at:

http://learnmem.cshlp.org/content/9/5/293.full.html\#ref-list-1

License

Email Alerting Receive free email alerts when new articles cite this article - sign up in the box at the Service top right corner of the article or click here. 